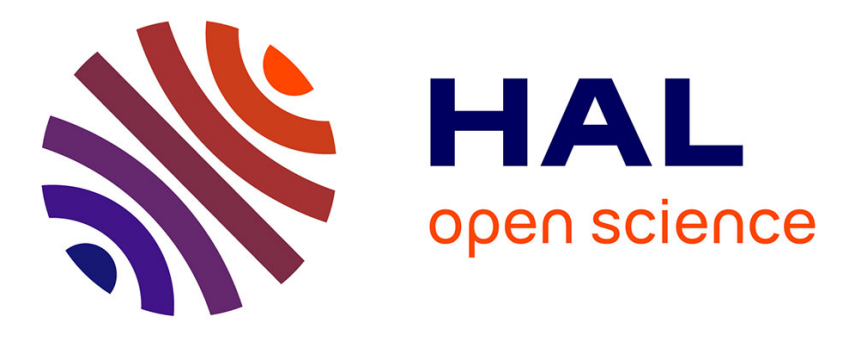

\title{
Understanding the $\mathrm{g}$-tensors of perchlorotriphenylmethyl and Finland-type trityl radicals
}

Paul Demay-Drouhard, H.Y.V. Ching, Christophe Decroos, Régis Guillot, Yun Li, Leandro Tabares, Clotilde Policar, Helene C Bertrand, Sun Un

\section{To cite this version:}

Paul Demay-Drouhard, H.Y.V. Ching, Christophe Decroos, Régis Guillot, Yun Li, et al.. Understanding the $\mathrm{g}$-tensors of perchlorotriphenylmethyl and Finland-type trityl radicals. Physical Chemistry Chemical Physics, 2020, 10.1039/d0cp03626a . hal-02938076

\section{HAL Id: hal-02938076 https://hal.science/hal-02938076}

Submitted on 9 Nov 2020

HAL is a multi-disciplinary open access archive for the deposit and dissemination of scientific research documents, whether they are published or not. The documents may come from teaching and research institutions in France or abroad, or from public or private research centers.
L'archive ouverte pluridisciplinaire HAL, est destinée au dépôt et à la diffusion de documents scientifiques de niveau recherche, publiés ou non, émanant des établissements d'enseignement et de recherche français ou étrangers, des laboratoires publics ou privés. 


\section{Understanding the $g$-tensors of Perchlorotriphenylmethyl and Finland-type Trityl radicals}

Received 00th January 20xx, Accepted 00th January 20xx

DOI: $10.1039 / x 0 x x 00000 x$

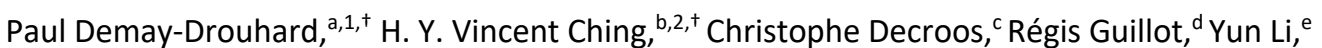
Leandro C. Tabares, ${ }^{b}$ Clotilde Policar, ${ }^{a^{*}}$ Helene C. Bertrand, ${ }^{a^{*}}$ and Sun Un ${ }^{b^{*}}$

\begin{abstract}
The $285 \mathrm{GHz}$ EPR spectra of perchlorotriphenylmethyl and tetrathiatriarylmethyl radicals in frozen solution have been accurately measured. The relationship between their molecular structures and their $g$-tensors has been investigated with the aid of DFT calculations, revealing that the degree of spin density delocalization away from the central methylene carbon is an important determining factor of the $g$-anisotropy. In particular, the small amount of spin densities on the $\mathrm{Cl}$ or $\mathrm{S}$ heteroatoms at the 2 and 6 positions with respect to the central carbon have the strongest influence. Furthermore, the amount of spin densities on these heteroatoms and thus the anisotropy can be modulated by the protonation (esterification) state of the carboxylate groups at the 4 position. These results provide unique insights into the $g$-anisotropy of persistent trityl radicals and how it can be tuned.
\end{abstract}

\section{Introduction}

Stable triphenylmethyl (trityl) radicals have been used in a wide variety of fields including magnetic materials, ${ }^{1-3}$ molecular switches $^{4,5}$ donor-acceptor systems, ${ }^{6-8}$ molecular junctions, ${ }^{9,10}$ dynamic nuclear polarization (DNP), ${ }^{11-17}$ EPR distance measurements, ${ }^{18-27}$ and in situ and in vivo applications ${ }^{28}$ such as $\mathrm{MR}^{29-31}$ and EPR ${ }^{32-37}$ imaging. Perchlorotriphenylmethyl (PTM) ${ }^{38}$ and tetrathiatriarylmethyl (TAM) ${ }^{39}$ radicals are two classes of trityl radicals (Figure 1) that have received much attention. Two of their unique and much exploited electronic properties are their long phase memory time and narrow EPR spectrum even at the high magnetic

a. Laboratoire des Biomolécules, LBM, Département de Chimie, Ecole Normale Supérieure, PSL University, Sorbonne Université, CNRS, 75005 Paris, France.

b. Institute for Integrative Biology of the Cell, Department of Biochemistry,

Biophysics and Structural Biology, Université Paris-Saclay, CEA, CNRS UMR 9198, Gif-sur-Yvette, F-91198, France.

Aix Marseille Univ, CNRS, Centrale Marseille, iSm2, Marseille, France.

d. Institut de Chimie Moléculaire et des Matériaux d'Orsay, Université Paris-Sud, CNRS UMR 8182, Université Paris-Saclay, 91405 Orsay, France

e. Laboratoire de Chimie des Processus Biologiques, CNRS UMR 8229, Collège de France, PSL University, Sorbonne Université, 11 Place Marcelin Berthelot, 75231 Paris Cedex 05, France.

1.Current address: Department of Chemistry, York University, 4700 Keele Street, Toronto, Ontario M3J 1P3, Canada.

2. Current address: BIMEF - Department of Chemistry, and ELCAT-Faculty of Applied Engineering, University of Antwerp, Universiteitsplein1, B-2610 Antwerp, Belgium.

†These authors contributed equally.

*Authors to whom correspondence should be addressed: sun.un@cea.fr helene.bertrand@ens.psl.eu, clotilde.policar@ens.psl.eu

Electronic Supplementary Information (ESI) available: [details of any supplementary information available should be included here]. See DOI: 10.1039/x0xx00000x. fields used in modern NMR and high field EPR. The latter makes them appealing for DNP and long-range dipolar distance measurements. The narrowness of their EPR spectra in part arises from their lack of strong hyperfine interactions, in particular to ${ }^{1} \mathrm{H}$ and ${ }^{14} \mathrm{~N}$ nuclei as is the case for nitroxides radicals. Moreover, the $g$-tensors of PTM and TAM radicals have small anisotropies. For most organic radicals, the largest contribution to their $g$-tensors arises from spin-orbit coupling. For a doublet-state $(S=1 / 2)$ radical, the atom-localized approximation for this contribution is given by ${ }^{40}$ :

$$
g_{S O}^{i i}=2 \sum_{n \neq p, p} \frac{\sum_{k, k^{\prime}} \zeta_{k}\left\langle\chi_{k^{\prime}}^{(p)}\left|l_{k^{\prime}}^{i}\right| \chi_{k^{\prime}}^{(n)}\right\rangle\left\langle\chi_{k}^{(n)}\left|l_{k}^{i}\right| \chi_{k}^{(p)}\right\rangle}{\varepsilon_{p}-\varepsilon_{n}}
$$

where $\chi_{k}^{(p)}$ and $\chi_{k}^{(n)}$ are the atomic orbitals of atom $k$ that has spinorbit coupling constant $\zeta_{k}$; its angular momentum operator along the $i$ direction (where $i=\mathrm{x}, \mathrm{y}, \mathrm{z}$ ) is $\boldsymbol{l}_{\boldsymbol{k}}^{\boldsymbol{i}}$. The linear combination of $\chi_{\boldsymbol{k}}^{(p)}$ atomic orbitals form the ground state singly occupied orbital (SOMO) molecular orbital (MO) $\boldsymbol{\psi}_{p}$ with energy $\boldsymbol{\varepsilon}_{\boldsymbol{p}}$ and, likewise, $\chi_{k}^{(n)}$ form $\psi_{n}$ with energy $\varepsilon_{n}$, the rest of the other molecular orbitals and energies. The denominator of Eq. 1 can be both positive or negative. The former corresponds to the excitation of an electron from a doubly occupied orbital to the SOMO and the latter the excitation of the unpaired electron to an unoccupied orbital. Positive contributions are typified by excitation of a low-lying nonbonding electron to the SOMO. This is the case from tyrosyl, semiquinone and nitroxide radicals. Another important factor revealed by Eq. 1 is the product of the ground state spin density of an atom and its spin-orbit coupling constant. Delocalization of unpaired electron density will tend to reduce $g$-anisotropy. When it is constrained to carbon atoms through a $\pi$-bonding network, the two angular momentum quantum mechanical terms will only have significant values if the excited-state is neither $\pi$ nor $\pi^{*}$ in character which typically lead to larger absolute 
values of $\varepsilon_{p}-\varepsilon_{n}$. By contrast, delocalization onto heavy atoms will increase $g$-anisotropy, since spin-orbit constants increase with $Z$ (nuclear charge). As just discussed, this is more so if the atoms in question also have electrons that occupy low-lying non-bonding $\mathrm{MO}$. Both TAM and PTM trityl radicals (Figure 1) have extensive electron delocalization, but also peripheral heavy atoms. However, despite having similar structures and heavy atoms that have spin-orbit coupling constants that are less than a factor two different ${ }^{41}$, their EPR spectra exhibit significant differences. ${ }^{13-16,42-44}$

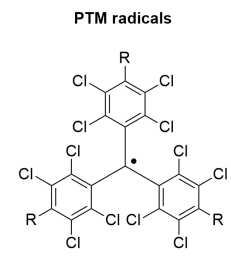

$\mathrm{R}=\mathrm{CO}_{2} \mathrm{Na}:$ PTMTC $\mathrm{R}=\mathrm{CO}_{2} \mathrm{H}: \mathrm{H}_{3}$ PTMTC $\mathrm{R}=\mathrm{CO}_{2}$ Et: PTMTE

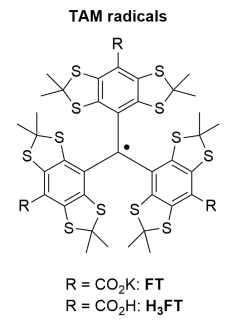

$\mathrm{R}=\mathrm{CO}_{2} \mathrm{H}: \mathrm{H}_{3} \mathrm{FT}$

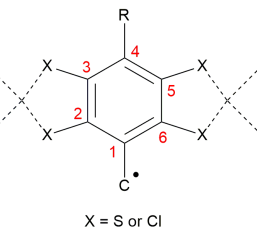

Figure 1. (left) Molecular structures of PTM and TAM radicals discussed in this work. (right) Numbering of carbon atoms of the aromatic rings.

Although it is straightforward to ascertain the relative differences in the broadness of the different trityl EPR spectra, high magnetic field EPR (HFEPR) has been generally required to quantitatively measure the small $g$-anisotropies of trityl radicals. For example, $3 \mathrm{~T} / 95 \mathrm{GHz}$ EPR measurements have shown that the principal $g$-values of the tricarboxylate derivative of PTM (PTMTC) were $g_{x}=2.00271$ and $g_{y}=$ $g_{z}=2.00005^{15}$ and those of the TAM Finland Trityl (FT) derivative were $[2.0030,2.0027,2.0021]^{44}$ (Here and in the following we will use this compact $\left[g_{x}, g_{y}, g_{z}\right]$ notation and use the convention $g_{x} \geq g_{y}$ $\geq g_{z}$. The subscripts in this notation do not necessarily carry any physical meaning nor are they necessarily related to the directions indicated in Eq. 1). Similarly, $8.5 \mathrm{~T} / 239 \mathrm{GHz}$ measurements determined that those of the TAM OX063 derivative were [2.00319, 2.00319, 2.00258]. ${ }^{16}$

However, the use of high magnetic field presents challenges in measuring the magnetic field at the sample in a reproducible and accurate manner. For example, specification of a given $g$-value to 4 decimal places implies the magnetic field has been measured to better than $1.7 \times 10^{-4} \mathrm{~T}$ (near $g_{\mathrm{e}}$ ) at a nominal field of $3.38983 \mathrm{~T}$ at 95 $\mathrm{GHz}$ and $5.1 \times 10^{-4} \mathrm{~T}$ at a nominal field $10.16951 \mathrm{~T}$ at $285 \mathrm{GHz}$ at the sample. Typically, the magnetic fields are measured as a function of the current driving the superconducting solenoid (for an exception see ${ }^{45}$ ). In principle, current measurements can afford accuracies to less than $0.1 \mathrm{mT}$. In practice, there are factors that limit the accuracy. For example, there are inductive effects that limit current measurements that depend on not only sweep rates but also magnet design (number of solenoids). Our experience with two different superconducting magnets is that there is also a degradation in calibration over time and can vary from sample to sample. There are also differences in the calculated magnetic field from the driving current and the actual magnetic field at the sample that can also be significant. Although these factors may be significant in determining the absolute magnetic field at the sample, for the most part they have a much less important role in measuring differences in magnetic fields and accuracies of better than $0.05 \mathrm{mT}$ can be achieved.
Without specification of the method, accuracy and reproducibility of magnetic field measurements, trityl $g$-values, even those obtained using high magnetic fields, need to be viewed with these limitations in mind.

Using $285 \mathrm{GHz} 10 \mathrm{~T}$ measurements on TAM and PTM type trityl radicals, we have examined the relationship between their $g$-tensors and their electronic structures. Both the relative and absolute accuracy of $g$-tensors were ensured by using $\mathrm{Mn}$ (II) and $\mathrm{Gd}(\mathrm{III})$ as calibration standards. The theoretical $g$-tensors derived from DFT calculations were in good agreement with the measured values and provide the means to understanding what electronic structural factors influenced the $g$-tensors. This knowledge will be helpful in tuning the structure of trityl radicals for a wide range of important applications.

\section{Results and Discussion}

Figure 2 shows the $285 \mathrm{GHz}$ cw-HFEPR spectra of FT, $\mathrm{H}_{3} \mathrm{FT}$, PTMTC, $\mathrm{H}_{3}$ PTMTC and PTMTE. Above them, examples of two spectra used to calibrate the magnetic field are also shown: one of two physically separated frozen solutions of the FT radical and Gd(III) coaxially mounted in the magnet and another of two frozen aqueous solutions of $\mathrm{Mn}$ (II) and Gd(III) in the same physical arrangement. The six Mn(II) hyperfine resonances of the latter spectrum were separated on average by $9.523 \mathrm{mT}$ with a standard deviation of $0.033 \mathrm{mT}$. This demonstrated that the field sweep was highly linear over this range. We have previously demonstrated that this linearity extends over a much larger field range, including where $\mathrm{Gd}(\mathrm{III})$ resonates, by incrementing the microwave frequency to produce an overlapping comb of $\mathrm{Mn}$ (II) magnetic field markers. ${ }^{46,47}$ The $g$-value of $\mathrm{Mn}$ (II) in water has been previously measured to be $g=2.00107 \pm 0.00003 .48$ Based on this value, the $g$-value of $\mathrm{Gd}(\mathrm{III})$ was determined to be 1.99191 with comparable precision. In light of the broadness of the spectral features of the trityl radicals that were much larger than this level of precision and the assumptions made in simulating and fitting the $g$-tensors of the radicals, in the following, the $g_{\text {eff }}(=f /(\nu B)$ where $\gamma=13.99623 \mathrm{GHz} / \mathrm{T}$ and $\mathrm{f}=285.0915 \mathrm{GHz}$ ) are reported to only 5decimal places.

The spectra were indicative of axial $g$-tensors. However, the direction of axiality was different with the TAM radicals having $g_{\mathrm{x}} \sim g_{\mathrm{y}}$ and the PTM radicals $g_{\mathrm{y}} \sim g_{\mathrm{z}}$. The overall $g$-anisotropy, defined as $\Delta g=g_{\mathrm{x}}-g_{\mathrm{z}}$, was significantly smaller for the former, $10 \times 10^{-4}$, compared to $25 \times 10$ ${ }^{4}$ for the latter. These values were significantly narrower than $70 \times 10$ 4 for stable nitroxide ${ }^{49,50}$ and $55 \times 10^{-4}$ for tyrosyl radicals, ${ }^{51}$ but still considerably broader than $5 \times 10^{-4}$ for a methyl radical in CO below 4.2 $\mathrm{K}^{52}$. Equally significant was that the TAM and PTM $g$-tensors were sensitive to the protonation state with protonation increasing the $g$ anisotropy. The $c w$-HFEPR spectrum of the deprotonated FT radical dissolved in water appeared to be narrower and less resolved than in 9:1 $\mathrm{H}_{2} \mathrm{O} /$ glycerol. At the higher radical and glycerol concentrations 


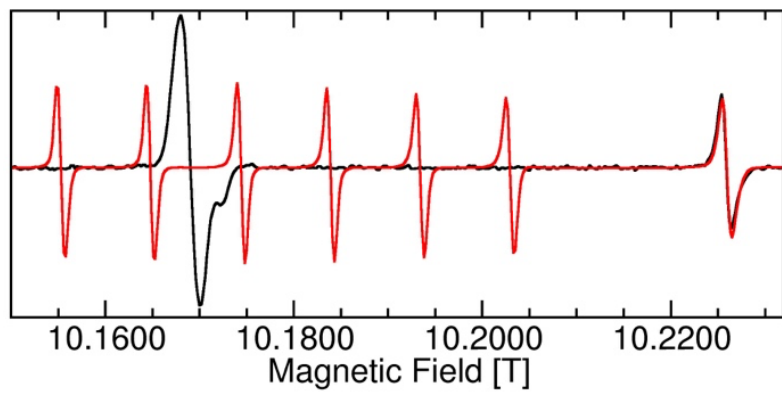

$\mathrm{g}_{\text {eff }}$

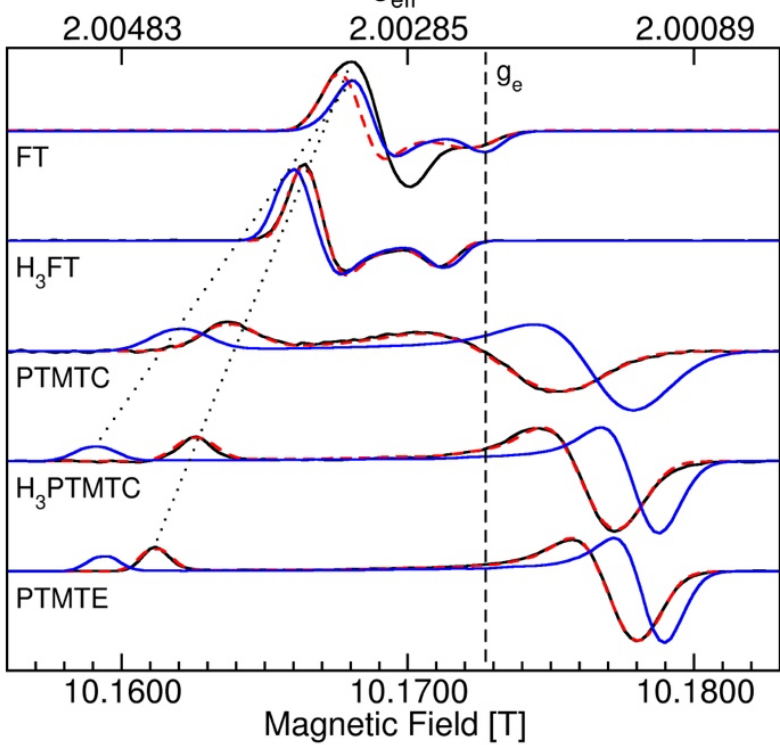

Figure 2. (top) $285 \mathrm{GHz}$ cw-HFEPR spectrum of coaxially mounted frozen aqueous solutions of: (black) FT radical and $\mathrm{Gd}$ (III) and (red) Mn(II) and Gd(III). (bottom) FT, $\mathrm{H}_{3} \mathrm{FT}$, PTMTC, $\mathrm{H}_{3}$ PTMTC, and PTMTE (black), fitted (dashed-red) and DFT simulations (blue). The dashed line indicates the free electron $g$-value $\left(g_{\mathrm{e}}\right)$ and the dotted black lines the trend in $\mathrm{g}_{\mathrm{x}}$.

that have been used for DNP (15 mM in 1:1 $\mathrm{H}_{2} \mathrm{O}$ /glycerol ${ }^{16}$ ), the spectral features were broader leading to lower resolution, but with essentially the same $g$-anisotropy.

A simple model was used to simulate and fit the spectra. This model consisted of the three-principal $g$-values and three parameters that described the Gaussian distribution of each of these three principal $g$-values. This meant that the distribution in $g$-tensor and any other anisotropic inhomogeneous contributions to the lineshape were assumed to be independent of each other and coaxial with the three principal directions of the $g$-tensor. The powder spectra generated from these values were then convolved with a derivative Gaussian function to obtain derivative powder patterns and account for the magnetic field modulation. The only significant factor in this convolution was the width of the Gaussian function. Together there were seven parameters and a scaling factor used to simulate the measured spectra. This model was fitted to the experimental data using a standard nonlinear least squares algorithm that minimized the root-mean-squared difference between the model and data. As can be seen in Figure 2 with the exception of the spectrum of the FT radical, simulations based on this model fit the experimental data extremely well. The Gaussian convolution widths closely matched
Table 1. Measured and calculated B3LYP/6-31+G(d,p) DFT $g$ tensors of the TAM and PTM and radicals. The measured values and their corresponding distributions (in parenthesis) were obtained from simulations.

\begin{tabular}{|c|c|c|c|c|c|}
\hline Radical & $g_{\mathrm{x}}$ & $g_{\mathrm{y}}$ & $g_{2}$ & $g_{\text {iso }}$ & $\Delta g$ \\
\hline \multicolumn{6}{|l|}{ FT } \\
\hline \multirow{2}{*}{ Measured $^{a}$} & 2.00339 & 2.00301 & 2.00233 & 2.00291 & 0.00106 \\
\hline & $(0.00002)$ & $(0.00004)$ & (0.00008) & & \\
\hline Measured $^{c}$ & 2.0030 & 2.0027 & 2.0021 & 2.0026 & 0.0009 \\
\hline $\mathrm{DFT}^{a}$ & 2.00320 & 2.00309 & 2.00228 & 2.00286 & 0.00092 \\
\hline$\Delta^{b}$ & -0.00019 & 0.0008 & -0.00005 & -0.00005 & -0.00014 \\
\hline \multicolumn{6}{|l|}{$\mathrm{H}_{3} \mathrm{FT}$} \\
\hline \multirow{2}{*}{ Measured $^{a}$} & 2.00358 & 2.00340 & 2.00262 & 2.00320 & 0.00096 \\
\hline & $(0.00002)$ & $(0.00004)$ & $(0.00004)$ & & \\
\hline $\mathrm{DFT}^{a}$ & 2.00361 & 2.00342 & 2.00262 & 2.00322 & 0.00099 \\
\hline$\Delta$ & 0.00003 & 0.00002 & 0.00000 & 0.00002 & 0.00003 \\
\hline Protonation Shift & 0.00019 & 0.00039 & 0.00029 & & \\
\hline \multicolumn{6}{|l|}{ PTMTC } \\
\hline \multirow{2}{*}{ Measured ${ }^{a}$} & 2.00410 & 2.00236 & 2.00176 & 2.00274 & 0.00234 \\
\hline & $(0.00001)$ & $(0.00026)$ & $(0.00021)$ & & \\
\hline Measured ${ }^{d}$ & 2.00271 & 2.00005 & 2.00005 & 2.00009 & 0.00266 \\
\hline $\mathrm{DFT}^{a}$ & 2.00443 & 2.00149 & 2.00148 & 2.00247 & 0.00295 \\
\hline$\Delta$ & 0.00033 & -0.00087 & -0.00028 & 0.00027 & 0.00061 \\
\hline \multicolumn{6}{|l|}{$\mathrm{H}_{3}$ PTMTC } \\
\hline \multirow{2}{*}{ Measured $^{a}$} & 2.00429 & 2.00168 & 2.00132 & 2.00243 & 0.00297 \\
\hline & $(0.00000)$ & $(0.00007)$ & $(0.00007)$ & & \\
\hline $\mathrm{DFT}^{a}$ & 2.00498 & 2.00120 & 2.00116 & 2.00245 & 0.00382 \\
\hline$\Delta$ & 0.00069 & -0.00048 & -0.00016 & 0.00002 & 0.00085 \\
\hline Protonation Shift & 0.00019 & -0.00068 & -0.00044 & & \\
\hline \multicolumn{6}{|l|}{ PTMTE } \\
\hline \multirow{2}{*}{ Measured $^{a}$} & 2.00458 & 2.00156 & 2.00125 & 2.00246 & 0.00333 \\
\hline & $(0.00000)$ & $(0.00011)$ & $(0.00010)$ & & \\
\hline $\mathrm{DFT}^{a, e}$ & 2.00493 & 2.00120 & 2.00117 & 2.00243 & 0.00377 \\
\hline$\Delta$ & 0.00035 & -0.00036 & -0.00008 & -0.00003 & 0.00044 \\
\hline Esterification Shift & 0.00048 & -0.00080 & -0.00051 & & \\
\hline \multicolumn{6}{|l|}{ Methyl } \\
\hline $\begin{array}{l}\text { Measured }^{f} \\
\text { (CO matrix) }\end{array}$ & 2.0027 & 2.0027 & 2.0022 & 2.0025 & 0.0005 \\
\hline $\mathrm{DFT}^{\mathrm{a}}$ & 2.0029 & 2.0029 & 2.0022 & 2.0027 & 0.0007 \\
\hline
\end{tabular}

${ }^{a}$ this work, ${ }^{b}$ difference between DFT and measured, ${ }^{c}$ ref ${ }^{44}$,

${ }^{d}$ ref $^{15},{ }^{e}$ modeled as the methyl ester derivative and ${ }^{f}{ } f^{52}$.

the amplitude of magnetic field modulation used to record the data. The anisotropic contributions to the inhomogeneous lineshape were,

if any, small. The best fits to this simple model were rhombic. The size of these distributions and the fitted principal $g$-values are tabulated in Table 1.

The model could not be fitted to the entirety of the FT radical spectrum. However, as Figure 3 shows, the model did fit the rising and falling edges when the minimization was constrained to these regions. The difference between the spectrum and this constrained fit was very similar to the spectrum of $1 \mathrm{mM}$ radical in water. This suggested that the FT radical spectrum was composed of two components, a resolved component with a $g$-anisotropy of 0.0011 and another with substantial smaller $g$-anisotropy. One possible explanation for the multiple spectral contribution was the presence of aggregates in the sample due to the lipophilicity of the molecule. 


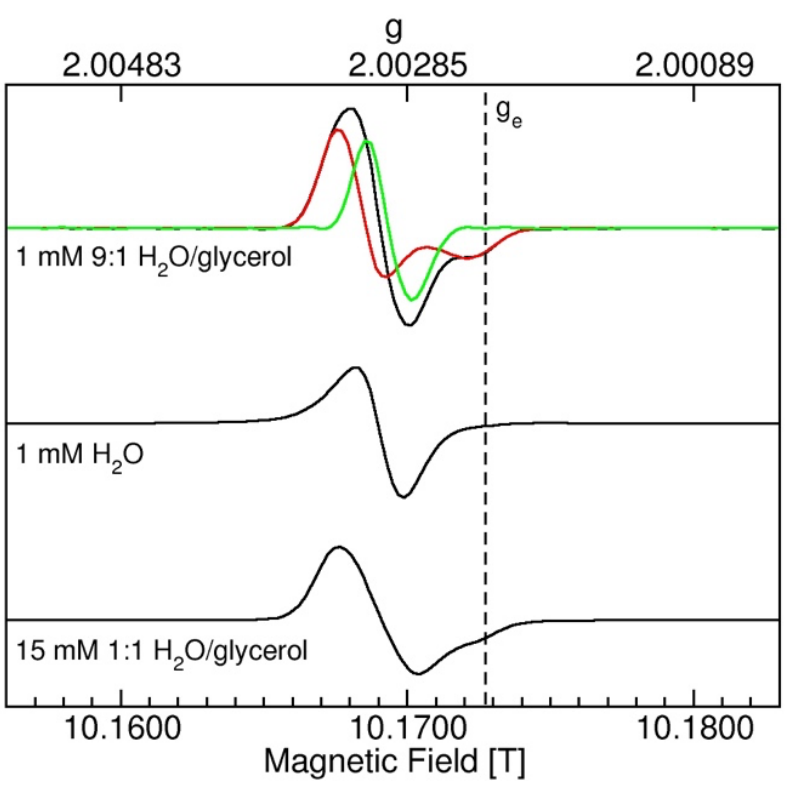

Figure 3. $285 \mathrm{GHz} c w$-HFEPR spectra of FT in 9:1 $\mathrm{H}_{2} \mathrm{O}$ /glycerol, and subtraction of the fit from the experimental (green). Middle: spectrum of FT in aqueous solution (without glycerol). Bottom: spectrum of FT in typical DNP conditions.

Under conditions that were similar to those previously reported for DNP measurements ${ }^{17,53,54}$ (15 $\mathrm{mM} \mathrm{H}_{2} \mathrm{O} /$ glycerol 1:1 solution), the spectrum of FT also appeared to contain an unresolved aggregation component. Compared to the 9:1 $\mathrm{H}_{2} \mathrm{O} / \mathrm{glycerol}$ sample no changes in the $g$-values were expected, but rather the amount of aggregation component. The spectral features observed in the $1: 1 \mathrm{H}_{2} \mathrm{O} /$ glycerol sample were similar to those reported for a FT derivative, OX63, obtained at $239.2 \mathrm{GHz}$ under the same sample conditions. ${ }^{16}$. Taken together, our observations are consistent with the spontaneous formation of spherical nanoparticles and fibers by FT radical that have been recently reported. ${ }^{55}$

The principal $g$-values of the FT and PTMTC radicals have been previously reported. ${ }^{15,44}$ For the former, the values reported in this study and the previous ones were in good agreement, the main difference being $3 \times 10^{-4}$ in the isotropic $g$-values. For the latter, isotropic $g$-values differed by $26 \times 10^{-4}$. However, there was closer agreement in $\Delta g$ values. This suggested the differences between the previously reported values and those reported here were due to accuracy in the absolute magnetic field calibration. Neither of these previous reports addressed the accuracy of the $g$-values.

Although the variation among the five trityl radicals is small, it was evident that their $g$-tensors were sensitive to the differences in electronic structure and environment. In addition to the theory developed by Stone ${ }^{40,56}, g$-tensors of organic radicals were analyzed using Density Functional Theory (DFT) calculations. The B3LYP/6$31+G(D, P)$ combination of hybrid density functional and basis-set was used to geometry optimized the model structures of the five trityl radicals, as well as to calculate the $g$-tensors of the radicals ${ }^{57}$. These calculations took into account the solvent using the Polarizable Continuum Model. ${ }^{58}$ They did not account for any specific solventradical interactions, such as hydrogen bonding between water
Table 2. The total B3LYP/6-31+G(D,P) Hirshfeld spin densities for selected atom types $(\mathrm{X}=\mathrm{S}$ or $\mathrm{Cl})$.

\begin{tabular}{ccccc}
\hline & Center & $\mathrm{C}_{2,6}$ & $\mathrm{C}_{4}$ & $\mathrm{X}-\left(\mathrm{C}_{2,6}\right)$ \\
\hline $\mathrm{FT}$ & 0.42 & 0.36 & 0.17 & 0.09 \\
\hline $\mathrm{H}_{3} \mathrm{FT}$ & 0.43 & 0.35 & 0.14 & 0.10 \\
\hline PTMTC & 0.49 & 0.33 & 0.15 & 0.07 \\
\hline H $_{3}$ PTMTC & 0.51 & 0.33 & 0.14 & 0.08 \\
\hline PTMTE & 0.50 & 0.33 & 0.14 & 0.08 \\
\hline
\end{tabular}

molecules and carboxylate groups in the case of FT and PTMTC. The optimized structures were found to be in good agreement with previously reported X-ray crystallographic structures. ${ }^{59-61}$ Most of the unpaired electron spin density was localized on the central carbon, but the amount was only about 42 to $51 \%$. As can be seen from Table 2, the rest of spin density was localized onto the 2,6 and 4 carbons and the heteroatoms bonded to the 2 and 6 carbons. Protonation and esterification of the peripheral carboxylate groups lead to an increase in spin density at the center carbon and position 2 and 6 heteroatoms and to a decrease at $C_{2,6}$ and $C_{4}$.

The DFT derived principal $g$-values are reported in Table 1 and simulations based on them are shown in Figure 2. The DFT calculations captured the differences in the $g$-tensors of PTM and TAM radicals. The calculated isotropic $g$-values of four of the five radicals were within 0.00005 of their measured values. The largest difference of 0.0003 for the PTMTC was in part associated with the noticeably large distribution in g-values. Except for FT (see above), the calculated g-anisotropies were over-estimated by as much as 0.0009 . However, they nearly quantitatively predicted the influence of the peripheral carboxyl groups.

The main contribution to the $g$-tensors is the orbital Zeeman/spinorbit contribution (the contributions to each of the DFT derived $g$ tensors are shown in the $\mathrm{SI}$ ). The relativistic and diamagnetic components were not only small, but also essentially cancelled each other leaving a difference of $5 \times 10^{-5}$. Hence, the departure from the $g_{e}$, as depicted in Figure 2, was a measure of the larger remaining orbital Zeeman/spin-orbit contribution. In the framework of Stone's theory, shifts to values lower than $g_{e}$ arise from mixing of the ground state with excited states that results from the excitation of the unpaired electron in the singly occupied molecular orbital (SOMO) to a higher unoccupied state. By contrast, $g$-values above $g_{e}$ originate from mixing of the ground state with an excited state arising from the excitation of an electron from a lower doubly occupied state to the SOMO.

The former is the case for the PTM $g_{y}$ and $g_{z}$ values and the latter, for the FT $g$-tensor as a whole. These differences between the TAM and PTM radicals can be qualitatively understood from their ground-state SOMO and lowest unoccupied molecular orbitals (LUMO). The significant $\pi^{*}$-like interactions of the $C_{2,6}$ sulfur $p_{z}$ orbitals with the center carbon $p_{z}$ orbital make the FT SOMO more spherically distributed about the central carbon giving the SOMO no significant directionality. This is apparent in the region delimited by the black circles in Figure 4. This spherical distribution results in lower $g$ - 

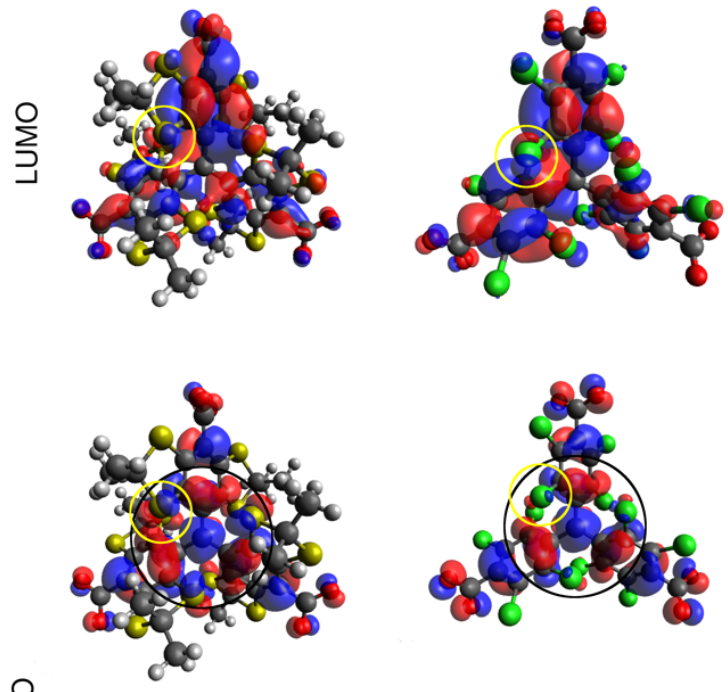

$\sum_{\substack{O \\ \hdashline}}^{0}$

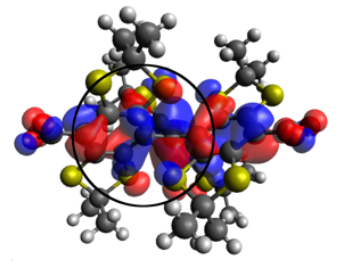

FT

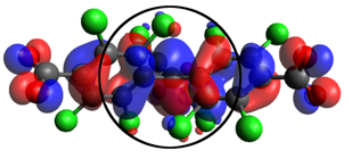

PTMTC
Figure 4. The LUMO (top row) and two orthogonal views of the SOMO of the FT (left) and PTMTC (right) radicals obtained from the DFT calculations (isosurface cutoff: 0.02 , figure created with Avogadro ${ }^{83}$, see Supporting Information for more detailed graphics material).

anisotropy. This is not so for the PTMTC SOMO which has three distinct directions, one along the $p_{z}$ and two in the perpendicular plane. Although $p_{z}$ orbitals of the $C_{2,6}$ chlorine atoms do participate in $\pi^{*}$-like interactions with the center carbon $p_{z}$ orbital, their contributions are much smaller than those of the FT radicals. The SOMO heteroatoms circled in yellow in Figure 4 demonstrate this. In the case of LUMOs, the FT $C_{2,6}$ sulfur atoms $p_{z}$ orbitals are involved in anti-bonding interactions. By contrast for the PTM radicals, the $p$ orbitals of the $C_{2,6}$ chlorine atoms are non-bonding in character. In this case, the spin-orbit mixing of SOMO and LUMO would lead to shift the $g$-values to lower values since $\varepsilon_{\mathrm{p}}-\varepsilon_{\mathrm{n}}$ is negative and would explain why the PTM $g_{y}$ and $g_{z}$ values are below $g_{e}$. The comparably important FT orbitals were further in energy with many of the lowlying excited states involving sulfur $\pi$ and $\pi^{*}$ bonding interactions. The nearest excited state(s) that contribute to the $g$-tensor evidently were those involving the excitation of an electron from a doubly occupied state to the SOMO having significant contribution from the $p_{x}$ or $p_{y}$-orbitals of the 2 and 6 position sulfur atoms. These would result in a positive spin-orbit contribution. Although the ground state spin densities of the $\mathrm{C}_{2,6}$ heteroatoms are significantly larger for FT radicals, their effect on the $g$-values is largely diminished by the energy difference term while the opposite is true for the PTM radicals with the energy difference having a larger effect.
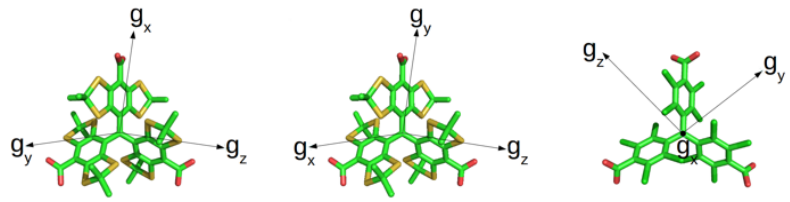

Figure 5. Orientation of the $g$-tensors of the FT (left), $\mathrm{H}_{3} \mathrm{FT}$ (center) and PTMTC (right). The view is perpendicular to the plane defined by the center $C$ and the three $C_{1}$ atoms. Hydrogens have been omitted for clarity (figure created with $\mathrm{PyMOL}^{82}$ ).

Not only were the $g$-anisotropies of FT radicals significantly smaller but the DFT calculations predicted that the $g_{x, y}$-directions are inverted upon deprotonation (Figure 5). By contrast, neither protonation nor esterification affected the $g$-tensor orientation in the PTM radicals (Figure 5). The trityl radicals are more complex than $\pi$-planar radicals such as semiquinones and tyrosyl radicals. For such planar radicals, the magnitude and direction of effects such as hydrogen bonding can be understood and rationalized in terms of spin polarization, $n \rightarrow \pi^{*}$ transition energy and atomic orbit coupling terms such as $\left\langle p_{x}\left|I_{y}\right| p_{z}\right\rangle$, the directionality of which is well defined. As can be seen from the spin densities in Table 2, protonation increases the ground state spin density of the $C_{2,6}$ heteroatoms. This increases their atomic orbital spin-orbit contributions to the $g$ tensors. This is consistent with the measurements which show that for the FT radical, all three principal $g$-values are further shifted away from $g_{\mathrm{e}}$ upon protonation. The same is true for PTM radicals except the shifts are in both directions with respect to ge. Hence, the larger $g$-anisotropies of protonated (and esterified) forms appear to be in part due to increase in spin densities at the heteroatoms. The energy differences between the coupled excited and ground states $\left(\varepsilon_{p}-\varepsilon_{n}\right)$ are also likely to contribute, but not in a direct way since the carboxylate groups carry virtually no spin density ( $<0.01$ in total). The effect of protonation on the direction of $g$-tensors appears to reflect the three-dimensional nature of the unpaired spin density of the trityl radicals. In the case of PTM radicals that have well-defined directions, the $g$-tensor orientation remained unchanged. The more spherically distributed FT radicals also have smaller $g$-anisotropies causing the directionality of the $g$-tensor to be sensitive to small changes.

In general, the heteroatoms in the 2 and 6 position appear to play an important role in the FT and PTM radical $g$-tensors. The more than a factor of two larger $g$-anisotropies of the PTM radicals compared to those of the FT's mirrors the 1.5 ratio of atomic spin-orbit coupling constants of sulfur and chlorine. ${ }^{41}$ By contrast, the carbon atoms are not likely to be as important. Although they carry most of the unpaired electron spin density, the central carbons of the TAM and PTM trityl radicals do not play a significant role in determining the $g$ tensors of either of these radicals. The reasons for this are the same as those that result in a small $g$-anisotropy for the methyl radical (Table 1), the unpaired spin density of which resides almost entirely on the $p_{z}$ orbital of the carbon atom. In spite of the highly localized spin density, the spin-orbit contribution is very small because the contribution from the terms $\left\langle p_{x}\left|I_{y}\right| p_{z}\right\rangle$ and $\left\langle p_{y}\left|I_{x}\right| p_{z}\right\rangle$ in Eq. 1 involve orbitals that are involved in covalent bonds and are small, and $\left(\varepsilon_{\mathrm{p}}-\right.$ $\varepsilon_{n}$ ) of these terms will be large. Consequently, the spin-orbit 
contribution will be small. With less localized spin density than the methyl radical, the atomic spin-orbit contribution from the center $C$ atom in the TAM and PTM radicals would be expected to be less and therefore unlikely to be the determining factor in the $g$-anisotropy. This suggests that in terms of designing trityl radicals it is likely to be more useful to focus on the nature of heteroatoms and $\mathrm{R}\left(\mathrm{C}_{4}\right)$-groups. In this context the TAM and PTM molecules can be considered as different radicals rather than derivatives of the simple Gomberg triphenylmethyl radical.

With these results in hand it is possible to formulate approaches for obtaining persistent trityl radicals with even smaller $g$-anisotropies. The spin-orbit constants of heteroatoms at the 2 and 6 positions should be as small as possible and their spin densities minimal. Extended spin delocalization over the carbon backbone trityl core is desirable. The mesityl-substituted tri(9-anthryl)methyl radical ${ }^{62}$ is an example of this. Another possibility would be to tune the spin delocalization using the 4 positions of the trityls. Extended delocalization would also reduce any contributions from proton hyperfine interactions. Incorporating aromatic moieties at these positions or replacing the $\mathrm{CO}_{2} \mathrm{R}$ groups with more electronwithdrawing groups are likely to decrease spin density at the 2 and 6 position heteroatoms.

Trityl derivatives with smaller $g$-anisotropies, and thus narrower spectra, would be of interest for high field EPR dipolar distance measurements. The inherent sensitivity gains by going to higher field are offset by complications due to the broadening of the trityl EPR spectrum. The resulting partial excitation of the trityl EPR spectra can lead to orientation selection effects, which are not always desirable and make more sensitive single frequency experiments such as DQC or SIFTER challenging. ${ }^{21}$ Trityl radicals with lower $g$-anisotropies would help circumvent these limitations and increase their utility and appeal. The ability to rationally control the trityl g-anisotropies will help engineer and analyze novel trityl containing multi-radical species that display complex EPR spectra with dipolar and exchange interactions, such as trityl-nitroxide biradicals that have recently emerged as very promising paramagnetic polarizing agents for MAS DNP at high field. ${ }^{54}$

\section{Conclusions}

Using $c W$-HFEPR at $285 \mathrm{GHz}$ we have accurately determined the $g$ tensors of $\mathrm{FT}, \mathrm{H}_{3} \mathrm{FT}$, PTMTC, $\mathrm{H}_{3}$ PTMTC and PTMTE trityl radicals in frozen solution. The differences between their $g$-tensors were rationalized using DFT calculations. Analysis of the SOMO and LUMO orbitals of the trityl radicals provided a qualitative explanation of the differences between their $g$-tensors. Our results suggest that the preparation of trityl radicals where the spin density is more delocalized over the triphenylmethyl core and away from heteroatoms would potentially yield derivatives with even lower $g$ anisotropies, making them more advantageous for many applications.

\section{Material and methods}

General: ${ }^{1 \mathrm{H}}$ and ${ }^{13} \mathrm{C}$ NMR spectra were recorded on a Bruker Avance 300 spectrometer using solvent residuals as internal references. The following abbreviations are used: singlet $(\mathrm{s})$, triplet $(\mathrm{t})$, quadruplet (q). Mass spectrometry services were provided by the ICMMO (Université Paris Sud, Orsay, France). The following abbreviations are used: HRMS (high resolution mass spectrometry), atmospheric pressure chemical ionization (APCI), electrospray (ESI). TLC analysis was carried out on silica gel (Merck 60F-254) with visualization at 254 and $366 \mathrm{~nm}$. Preparative flash chromatography was carried out with Merck silica gel (Si 60, 40-63 mm). All reactions were performed under an $\mathrm{Ar}$ inert atmosphere unless otherwise stated. Dry tetrahydrofuran (THF) was purchased from Sigma and used without further purification. MilliQ ${ }^{\mathrm{TM}}$ water was used for all experiments requiring water. All other solvents and reagents were purchased from commercial sources and used without further purification. The tripotassium salt of Finland trityl (FT) was synthesized according to a literature procedure. ${ }^{63}$ The synthesis of PTMTE and $\mathrm{H}_{3}$ PTMTC is summarized in Scheme S1.

Synthesis: Tris(2,3,5,6-tetrachlorophenyl)methane (2) 1,2,4,5Tetrachlorobenzene 1 ( $9.6 \mathrm{~g}, 44 \mathrm{mmol}, 9.0 \mathrm{eq}), \mathrm{AlCl}_{3}$ (730 mg, 5.2 $\mathrm{mmol}, 1.06 \mathrm{eq}$ ) and chloroform ( $0.4 \mathrm{~mL}, 4.9 \mathrm{mmol}, 1.0 \mathrm{eq})$ were mixed in a sealed high-pressure tube. The resulting mixture was heated at $160{ }^{\circ} \mathrm{C}$ for $45 \mathrm{~min}$ and cooled to rt. $\mathrm{CH}_{2} \mathrm{Cl}_{2}$ was added and the black suspension was sonicated for $30 \mathrm{~min}$ and washed with aq. $0.1 \mathrm{M} \mathrm{HCl}(1 \times), \mathrm{H}_{2} \mathrm{O}(1 \times)$, and sat. aq. $\mathrm{NaCl}(1 \times)$. The organic layer was dried over $\mathrm{Na}_{2} \mathrm{SO}_{4}$, filtered and concentrated. Column chromatography $\left(\mathrm{SiO}_{2}, 1300 \mathrm{~g}, \varnothing 9 \mathrm{~cm}, 100 \%\right.$ cyclohexane) followed by pentane washings afforded tris(2,3,5,6tetrachlorophenyl)methane $\mathbf{2}(1.181 \mathrm{~g}, 1.796 \mathrm{mmol}, 37 \%)$ as a white solid. ${ }^{1} \mathrm{H}-\mathrm{NMR}\left(\mathrm{CDCl}_{3}, 300 \mathrm{MHz}\right): \delta 7.65(\mathrm{~s}, 3 \mathrm{H}), 6.98(\mathrm{~s}, 1 \mathrm{H}) ;{ }^{13} \mathrm{C}-\mathrm{NMR}$ $\left(\mathrm{CDCl}_{3}, 75 \mathrm{MHz}\right): \delta 138.7\left(\mathrm{C}_{\mathrm{q}}\right), 134.5\left(\mathrm{C}_{\mathrm{q}}\right), 133.7\left(\mathrm{C}_{\mathrm{q}}\right), 133.4\left(\mathrm{C}_{\mathrm{q}}\right), 132.6$ $\left(\mathrm{C}_{\mathrm{q}}\right), 130.5(\mathrm{CH}), 56.2(\mathrm{CH})$; HRMS (APCl): $m / z=616.6886[\mathrm{M}-\mathrm{Cl}]^{+}$ (found), 616.6881 calcd. for $\mathrm{C}_{19} \mathrm{H}_{4} \mathrm{Cl}_{11}{ }^{+}$. Characterization in accordance with literature. ${ }^{64,65}$

Triethyl 4,4',4"-methanetriyltris(2,3,5,6-tetrachlorobenzoate) (3) Compound 2 (730 mg, $1.11 \mathrm{mmol}, 1.0 \mathrm{eq}$ ) was dissolved in dry THF (70 mL). TMEDA (530 $\mu \mathrm{L}, 3.55 \mathrm{mmol}, 3.2 \mathrm{eq})$ was added and the resulting solution was cooled to $-78^{\circ} \mathrm{C} . n$-BuLi $(1.6 \mathrm{M}$ in THF, $2.36 \mathrm{~mL}$, $3.77 \mathrm{mmol}, 3.4 \mathrm{eq}$ ) was added in one portion and the resulting mixture was stirred at $-78{ }^{\circ} \mathrm{C}$ for $2 \mathrm{~h}$. Ethyl chloroformate $(1.06 \mathrm{~mL}$, $11.1 \mathrm{mmol}, 10.0 \mathrm{eq}$ ) was added dropwise and the resulting solution was allowed to warm to $\mathrm{rt}$ for $15 \mathrm{~h}$ and concentrated. $\mathrm{H}_{2} \mathrm{O}$ was added and the mixture was extracted with DCM $(3 x)$. The combined organic layers were dried over $\mathrm{Na}_{2} \mathrm{SO}_{4}$, filtered and concentrated. Column chromatography (99:1 to 90:10 cyclohexane/EtOAc) afforded triethyl 4,4',4"-methanetriyltris(2,3,5,6-tetrachlorobenzoate) 3 (640 mg, $0.732 \mathrm{mmol}, 66 \%)$ as a white solid. ${ }^{1} \mathrm{H}-\mathrm{NMR}\left(\mathrm{CDCl}_{3}, 300 \mathrm{MHz}\right): \delta 7.00$ (s, $1 \mathrm{H}), 4.49$ (q, $J=7.1 \mathrm{~Hz}, 6 \mathrm{H}), 1.43(\mathrm{t}, J=7.1 \mathrm{~Hz}, 9 \mathrm{H})$; HRMS (APCl): $\mathrm{m} / \mathrm{z}=868.7303[\mathrm{M}+\mathrm{H}]^{+}$(found), 868.7282 calcd. for $\mathrm{C}_{28} \mathrm{H}_{17} \mathrm{Cl}_{12} \mathrm{O}_{6}{ }^{+}$. Characterization in accordance with literature. ${ }^{65,66}$

PTMTE Compound 3 ( $820 \mathrm{mg}, 0.938 \mathrm{mmol}, 1.0 \mathrm{eq}$ ) was dissolved in a mixture of dry DMSO $(30 \mathrm{~mL})$ and dry $\mathrm{Et}_{2} \mathrm{O}(135 \mathrm{~mL})$, and then powdered $\mathrm{NaOH}(750 \mathrm{mg}, 18.8 \mathrm{mmol}, 20.0$ eq) was added. The resulting mixture was stirred at $\mathrm{rt}$ for $24 \mathrm{~h}$ protected from light and filtered to a solution containing iodine $(1.05 \mathrm{~g})$ dissolved in dry $\mathrm{Et}_{2} \mathrm{O}$ $(55 \mathrm{~mL})$. The resulting solution was left undisturbed protected from light for $24 \mathrm{~h}$ and washed with sat. aq. $\mathrm{NaHCO}_{3}(1 \times)$, sat. aq. $\mathrm{NaCl}$ $(1 \times)$, and $\mathrm{H}_{2} \mathrm{O}(2 \times)$. The organic layer was dried over $\mathrm{Na}_{2} \mathrm{SO}_{4}$, filtered 
and concentrated. Column chromatography (95:5 to $80: 20$ cyclohexane/EtOAc) afforded PTMTE (672 $\mathrm{mg}, 0.770 \mathrm{mmol}, 82 \%$ ) as a red solid. $\mathrm{R}_{\mathrm{f}}\left(\mathrm{SiO}_{2}\right): 0.65$ (80:20 cyclohexane/EtOAc); HRMS (ESI):

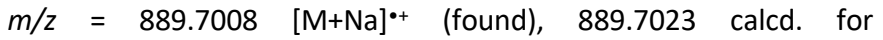
$\mathrm{C}_{28} \mathrm{H}_{15} \mathrm{Cl}_{12} \mathrm{NaO}_{6}{ }^{\circ+}$. Characterization in accordance with literature. ${ }^{65,66}$

H $_{3}$ PTMTC PTMTE (260 mg, $0.298 \mathrm{mmol}, 1.0 \mathrm{eq}$ ) was dissolved in $\mathrm{MeOH}$ ( $5 \mathrm{~mL}$ ). $\mathrm{KOH}$ ( $836 \mathrm{mg}, 14.9 \mathrm{mmol}, 50.0 \mathrm{eq}$ ) was added and the resulting mixture was refluxed for $48 \mathrm{~h}$ and cooled to $\mathrm{rt}$. $\mathrm{H}_{2} \mathrm{O}$ was added, the mixture was washed with $\mathrm{Et}_{2} \mathrm{O}(3 \times)$ and acidified with aq. $1 \mathrm{M} \mathrm{HCl}$ to obtain a red precipitate. This mixture was extracted with $\mathrm{Et}_{2} \mathrm{O}(3 \times)$ and the combined organic layers were dried over $\mathrm{Na}_{2} \mathrm{SO}_{4}$, filtered and concentrated to afford $\mathrm{H}_{3}$ PTMTC $(200 \mathrm{mg}, 0.253 \mathrm{mmol}$, $85 \%)$ as a red solid.

EPR sample preparation: Unless otherwise stated the concentration of all trityl EPR samples were $1 \mathrm{mM}$. $\mathrm{H}_{3} \mathrm{FT}, \mathrm{H}_{3}$ PTMTC and PTMTE were dissolved in 2-Me-THF and FT and PTMTC in 9:1 $\mathrm{H}_{2} \mathrm{O} /$ glycerol. Spectra were obtained at $15 \mathrm{~K}$ with modulation of $5 \mathrm{G}$ under non-saturating conditions except for PTMTC, for which the spectrum was obtained at $100 \mathrm{~K}$ and $10 \mathrm{G}$ modulation to achieve non-saturation. FT samples ( 1 or $15 \mathrm{mM}$ ) were prepared by dissolving $\mathrm{K}_{3} \mathrm{FT}$ in $\mathrm{H}_{2} \mathrm{O}$ with $10 \% \mathrm{v} / \mathrm{v}$ glycerol, $\mathrm{H}_{2} \mathrm{O}$, or $\mathrm{H}_{2} \mathrm{O}$ with $50 \% \mathrm{v} / \mathrm{v}$ glycerol. The $\mathrm{H}_{3} \mathrm{FT}$ sample was prepared by addition of one drop $(\approx 1 \mu \mathrm{L})$ of concentrated $\mathrm{HCl}(10 \mathrm{M})$ to an aqueous solution of $\mathrm{K}_{3} \mathrm{FT}(1 \mathrm{mM}, 500 \mu \mathrm{L})$. The precipitate was isolated by centrifugation and dissolved in 2-Me-THF (500 $\mu \mathrm{L})$. The PTMTC sample was prepared in situ by deprotonation of $\mathrm{H}_{3}$ PTMTC using excess $\mathrm{NaOH}$ (20 eq) in $\mathrm{H}_{2} \mathrm{O}$ with $10 \% \mathrm{v} / \mathrm{v}$ glycerol. The $\mathrm{H}_{3}$ PTMTC and PTMTE samples were prepared by dissolving in 2-MeTHF. The experimental setup consists of a $0.6 \mathrm{~mL}$ Eppendorf tube coaxially mounted within a $2 \mathrm{~mL}$ Nalgene ${ }^{\circledast}$ cryogenic vial that are typically used as sample tubes. A $85 \mu \mathrm{L}$ solution of $50 \mu \mathrm{M} \mathrm{GdCl}$ in $\mathrm{H}_{2} \mathrm{O}$ with $10 \% \mathrm{v} / \mathrm{v}$ glycerol was added to the Eppendorf tube, while the cryotube contained $300 \mu \mathrm{L}$ solution of either $50 \mu \mathrm{M} \mathrm{Mn}\left(\mathrm{ClO}_{4}\right)_{2}$ in $\mathrm{H}_{2} \mathrm{O}$ with $20 \% \mathrm{v} / \mathrm{v}$ glycerol or the radical samples.

EPR measurements: The $285 \mathrm{GHz}$ cw-HFEPR spectra were recorded on a locally constructed HFEPR spectrometer which has been previous described. The magnetic power supply had a digital accuracy of 0.5 G. ${ }^{67}$ To insure non-saturating conditions, the signal amplitude was monitored as a function power of the $95 \mathrm{GHz}$ synthesizer which drives the frequency tripler. The output power of the tripler was monotonic with respect to the $95 \mathrm{GHz}$ input power that we used in these experiments. The relative change in $285 \mathrm{GHz}$ output power was also monitored at the bolometer detector. A second criterion for non-saturating conditions was that the integration of spectra, after baseline correction, yielded a proper absorption line shape, in particular one where the baseline was zero on either side of the resonance. This criterion was found to be more stringent and could detect passage and saturation effects associated with modulation that have been documented in early works of Portis, ${ }^{68,69} \mathrm{Hyde}^{70,71}$ and Weger. ${ }^{72}$ For this reason, sufficiently large enough modulation amplitudes were used to fulfill this integrability condition. The largest modulation amplitude used was $10 \mathrm{G}$. The apparent inhomogeneous broadening was substantially larger and, thus, had little effect on the quality of spectra with respect to resolution.
Density Functional Calculations: Density functional calculations were carried out with Gaussian 09 (revision B.01)..$^{73}$ The B3LYP hybrid density functional ${ }^{74-77}$ and $6-31+G(d, p)$ basis set ${ }^{78-81}$ were used for geometry optimization and subsequent calculation of $g$-values. For FT and PTMTC, the calculation included water solvation and for $\mathrm{H}_{3} \mathrm{FT}$, $\mathrm{H}_{3}$ PTMTC and PTMTE, solvation in THF using the default polarizable continuum model. ${ }^{58}$

\section{Conflicts of interest}

There are no conflicts to declare.

\section{Acknowledgements}

This work was financially supported by ANR MnHFPELDOR, ANR-Deutsche Forschungsgemeinschaft (DFG) Chemistry (2011-INTB-1010-01, P.D.-D. PhD studentship and H.Y.V.C. post-doctoral fellowship) and has benefited from the biophysics platform of the Institute for Integrative Biology of the Cell supported by French Infrastructure for Integrated Structural Biology (FRISBI) ANR-10-INBS-05-05. We are very grateful to Drs. Dmitry Akhmetzyanov (University of Waterloo) and Melissa Van Landeghem (University of Antwerp) for fruitful and constructive discussions.

\section{Notes and references}

D. Maspoch, D. Ruiz-Molina, K. Wurst, N. Domingo, M. Cavallini, F. Biscarini, J. Tejada, C. Rovira, J. Veciana, Nat. Mat. 2003, 2, 190-195.

2 D. Maspoch, N. Domingo, D. Ruiz-Molina, K. Wurst, G. Vaughan, J. Tejada, C. Rovira, J. Veciana, Angew. Chem. Int. Ed. 2004, 43, 1828-1832.

3 A. Datcu, N. Roques, V. Jubera, I. Imaz, D. Maspoch, J.-P. Sutter, C. Rovira, J. Veciana, Chem. Eur. J. 2011, 17, 36443656. C. Sporer, I. Ratera, D. Ruiz-Molina, Y. Zhao, J. VidalGancedo, K. Wurst, P. Jaitner, K. Clays, A. Persoons, C. Rovira, et al., Angew. Chem. Int. Ed. 2004, 43, 5266-5268. C. Simão, M. Mas-Torrent, N. Crivillers, V. Lloveras, J. M. Artés, P. Gorostiza, J. Veciana, C. Rovira, Nat. Chem. 2011, 3, 359-364.

J. Guasch, L. Grisanti, V. Lloveras, J. Vidal-Gancedo, M. Souto, D. C. Morales, M. Vilaseca, C. Sissa, A. Painelli, I. Ratera, et al., Angew. Chem. Int. Ed. 2012, 51, 1102411028.

7 J. Guasch, L. Grisanti, M. Souto, V. Lloveras, J. VidalGancedo, I. Ratera, A. Painelli, C. Rovira, J. Veciana, J. Am. Chem. Soc. 2013, 135, 6958-6967.

M. Souto, M. V. Solano, M. Jensen, D. Bendixen, F. Delchiaro, A. Girlando, A. Painelli, J. O. Jeppesen, C. Rovira, I. Ratera, et al., Chem. Eur. J. 2015, 21, 8816-8825. N. Crivillers, C. Munuera, M. Mas-Torrent, C. Simão, S. T. Bromley, C. Ocal, C. Rovira, J. Veciana, Adv. Mat. 2009, 21, 1177-1181. 
S. Suchang Sangeeth, C. Rovira, J. Veciana, C. A. Nijhuis, Nat. Comm. 2016, 7, 12066.

11 J. H. Ardenkjær-Larsen, B. Fridlund, A. Gram, G. Hansson, L. Hansson, M. H. Lerche, R. Servin, M. Thaning, K. Golman, Proc. Natl. Acad. Sci. U.S.A. 2003, 100, 10158-10163. J. Leggett, R. Hunter, J. Granwehr, R. Panek, A. J. PerezLinde, A. J. Horsewill, J. McMaster, G. Smith, W. Köckenberger, Phys. Chem. Chem. Phys. 2010, 12, 58835892.

13 C. Gabellieri, V. Mugnaini, J. C. Paniagua, N. Roques, M. Oliveros, M. Feliz, J. Veciana, M. Pons, Angew. Chem. Int. Ed. 2010, 49, 3360-3362. J. C. Paniagua, V. Mugnaini, C. Gabellieri, M. Feliz, N. Roques, J. Veciana, M. Pons, Phys. Chem. Chem. Phys. 2010, 12, 5824-5829.

15 D. Banerjee, J. C. Paniagua, V. Mugnaini, J. Veciana, A. Feintuch, M. Pons, D. Goldfarb, Phys. Chem. Chem. Phys. 2011, 13, 18626-18637. L. Lumata, Z. Kovacs, A. D. Sherry, C. Malloy, S. Hill, J. Van Tol, L. Yu, L. Song, M. E. Merritt, Phys. Chem. Chem. Phys. 2013, 15, 9800-9807. G. Mathies, M. A. Caporini, V. K. Michaelis, Y. Liu, K.-N. Hu, D. Mance, J. L. Zweier, M. Rosay, M. Baldus, R. G. Griffin, Angew. Chem. Int. Ed. 2015, 54, 11770-11774. Z. Yang, Y. Liu, P. Borbat, J. L. Zweier, J. H. Freed, W. L. Hubbell, J. Am. Chem. Soc. 2012, 134, 9950-9952. G. W. Reginsson, N. C. Kunjir, T. Sigurdsson, O. Schiemann, Chem. Eur. J. 2012, 18, 13580-13584.

20 G. Y. Shevelev, O. A. Krumkacheva, A. A. Lomzov, A. A Kuzhelev, O. Y. Rogozhnikova, D. V Trukhin, T. I. Troitskaya, V. M. Tormyshev, M. V Fedin, D. V Pyshnyi, et al., J. Am. Chem. Soc. 2014, 136, 9874-9877.

21 D. Akhmetzyanov, P. Schöps, A. Marko, N. C. Kunjir, S. T. Sigurdsson, T. F. Prisner, Phys. Chem. Chem. Phys. 2015, 17, 24446-24451.

22 B. Joseph, V. M. Tormyshev, O. Y. Rogozhnikova, D. Akhmetzyanov, E. G. Bagryanskaya, T. F. Prisner, Angew. Chem. Int. Ed. 2016, 55, 11538-11542.

J. J. Jassoy, A. Berndhäuser, F. Duthie, P. K. Sebastian, G. Hagelueken, O. Schiemann, Angew. Chem. Int. Ed. 2017, $56,177-181$. A. A. Kuzhelev, O. A. Krumkacheva, G. Y. Shevelev, M. Yulikov, M. V. Fedin, E. G. Bagryanskaya, Phys. Chem. Chem. Phys. 2018, 20, 10224-10230. A. Giannoulis, Y. Yang, Y. J. Gong, X. Tan, A. Feintuch, R. Carmieli, T. Bahrenberg, Y. Liu, X. C. Su, D. Goldfarb, Phys. Chem. Chem. Phys. 2019, 21, 10217-10227. Y. Yang, B. Bin Pan, X. Tan, F. Yang, Y. Liu, X. C. Su, D. Goldfarb, J. Phys. Chem. Lett. 2020, 11, 1141-1147. N. Fleck, C. A. Heubach, T. Hett, F. R. Haege, P. P. Bawol, H. Baltruschat, O. Schiemann, Angew. Chem. Int. Ed. 2020, ASAP. V. V. Khramtsov, A. A. Bobko, M. Tseytlin, B. Driesschaert, Anal. Chem. 2017, 89, 4758-4771.

J. H. Ardenkjær-Larsen, I. Laursen, I. Leunbach, G. Ehnholm, L.-G. Wistrand, J. S. Petersson, K. Golman, J. Magn. Res. 1998, 133, 1-12.
M. C. Krishna, S. English, K. Yamada, J. Yoo, R. Murugesan, N. Devasahayam, J. A. Cook, K. Golman, J. H. ArdenkjærLarsen, S. Subramanian, et al., Proc. Natl. Acad. Sci. U.S.A. 2002, 99, 2216-2221. S. J. Nelson, J. Kurhanewicz, D. B. Vigneron, P. E. Z. Larson, A. L. Harzstark, M. Ferrone, M. Van Criekinge, J. W. Chang, R. Bok, I. Park, et al., Sci. Transl. Med. 2013, 5, 198ra108. P. Kuppusamy, P. Wang, M. Chzhan, J. L. Zweier, Magn. Res. Med. 1997, 37, 479-483.

G. He, Y. Deng, H. Li, P. Kuppusamy, J. L. Zweier, Magn. Res. Med. 2002, 47, 571-578.

M. Elas, B. B. Williams, A. Parasca, C. Mailer, C. A. Pelizzari, M. A. Lewis, J. N. River, G. S. Karczmar, E. D. Barth, H. J. Halpern, Magn. Res. Med. 2003, 49, 682-691.

K. Matsumoto, S. Subramanian, N. Devasahayam, T. Aravalluvan, R. Murugesan, J. A. Cook, J. B. Mitchell, M. C. Krishna, Magn. Res. Med. 2006, 55, 1157-63.

A. Samouilov, G. L. Caia, E. Kesselring, S. Petryakov, T. Wasowicz, J. L. Zweier, Magn. Res. Med. 2007, 58, 156166.

H. B. Elajaili, J. R. Biller, M. Tseitlin, I. Dhimitruka, V. V. Khramtsov, S. S. Eaton, G. R. Eaton, Magn. Reson. Chem. 2014, 53, 280-284.

M. Ballester, J. Riera, J. Castañer, C. Badía, J. M. Monsó, J. Am. Chem. Soc. 1967, 93, 2215-2225.

M. Jørgensen, F. Rise, S. Andersson, T. Almén, A. Aabye, L.G. Wistrand, H. Wikström, K. Golman, R. Servin, P. Michelsen, Hafslund Nycomed Innovation AB, Patent PCT WO91/12024, 1991.

A. J. Stone, Proc. R. Soc. Lond. A 1963, 271, 424-434.

A. Carrington, A. D. McLachlan, Introduction to Magnetic Resonance, with Applications to Chemistry and Chemical Physics. New York and London, Harper \& Row, 1967. F. M. Vigier, D. Shimon, V. Mugnaini, J. Veciana, A. Feintuch, M. Pons, S. Vega, D. Goldfarb, Phys. Chem. Chem. Phys. 2014, 16, 19218-19228.

D. Banerjee, D. Shimon, A. Feintuch, S. Vega, D. Goldfarb, J. Magn. Res. 2013, 230, 212-219.

A. J. Fielding, P. J. Carl, G. R. Eaton, S. S. Eaton, Appl. Magn. Reson. 2005, 28, 231-238.

S. Un, J. Bryant, R. G. Griffin, J. Magn. Res. Ser. A 1993, 101, 92-94.

S. Un, L. C. Tabares, N. Cortez, B. Y. Hiraoka, F. Yamakura, J. Am. Chem. Soc. 2004, 126, 2720-2726.

C. Hureau, G. Blondin, M. Cesario, S. Un, J. Am. Chem. Soc. 2003, 125, 11637-11645.

S. Un, Inorg. Chem. 2013, 52, 3803-3813.

F. Kurdzesau, B. Van Den Brandt, A. Comment, P. Hautle, S. Jannin, J. J. Van Der Klink, J. A. Konter, J. Phys. D Appl. Phys. 2008, 41, 155506.

J. Soetbeer, P. Gast, J. J. Walish, Y. Zhao, C. George, C. Yang, T. M. Swager, R. G. Griffin, G. Mathies, Phys. Chem. Chem. Phys. 2018, 20, 25506-25517.

S. Un, A. W. Rutherford, M. Atta, M. Atta, M. Fontecave, J. Am. Chem. Soc. 1995, 117, 10713-10719.

Y. A. Dmitriev, R. A. Zhitnikov, J. Low Temp. Phys. 2001, $122,163-170$. 
J. Wolber, F. Ellner, B. Fridlund, A. Gram, H. Jóhannesson, G. Hansson, L. H. Hansson, M. H. Lerche, S. Månsson, R. Servin, et al., Nucl. Instrum. Methods Phys. Res. A 2004, 526, 173-181.

F. Mentink-Vigier, G. Mathies, Y. Liu, A. L. Barra, M. A Caporini, D. Lee, S. Hediger, R. Griffin, G. De Paëpe, Chem. Sci. 2017, 8, 8150-8163.

I. Martin-Montesinos, J. C. Paniagua, A. Peman, M. Vilaseca, F. Luis, S. Van Doorslaer, M. Pons, Phys. Chem. Chem. Phys. 2016, 18, 3151-3158. D. Maspoch, D. Ruiz-Molina, K. Wurst, G. Vaughan, N. Domingo, J. Tejada, C. Rovira, J. Veciana, CrystEngComm 2004, 6, 573-578. D. Maspoch, N. Domingo, N. Roques, K. Wurst, J. Tejada, C. Rovira, D. Ruiz-Molina, J. Veciana, Chem. Eur. J. 2007, 13, 8153-8163.

57, 16516-16519.

A. J. Stone, Mol. Phys. 1963, 6, 509-515.

. Neese, J. Chem. Phys. 2001, 115, 11080-11096 2999-3093.

Y. Liu, F. A. Villamena, J. Sun, Y. Xu, I. Dhimitruka, J. L. Zweier, J. Org. Chem. 2008, 73, 1490-1497.

T. Nishiuchi, S. Aibara, T. Kubo, Angew. Chem. Int. Ed. 2018,

T. J. Reddy, T. Iwama, H. J. Halpern, V. H. Rawal, J. Org. Chem. 2002, 67, 4635-4639.

M. Ballester, J. Riera, J. Castañer, C. Rovira, O. Armet, Synthesis 1986, 64-66.

J. Frank, M. Elewa, M. M. Said, H. A. El Shihawy, M. ElSadek, D. Müller, A. Meister, G. Hause, S. Drescher, H. Metz, et al., J. Org. Chem. 2015, 80, 6754-6766.

V. Dang, J. Wang, S. Feng, C. Buron, F. A. Villamena, P. G. Wang, P. Kuppusamy, Bioorg. Med. Chem. Lett. 2007, 17, 4062-4065.

S. Un, P. Dorlet, A. W. Rutherford, Appl. Magn. Reson. 2001, 21, 341-361.

A. M. Portis, Phys. Rev. 1953, 91, 1071-1078.

A. M. Portis, Tech. Note No. 1, Sarah Mellon Scaife Radiation Laboratory, University of Pittsburgh, 1955. J. S. Hyde, Phys. Rev. 1960, 119, 1483-1492. J. S. Hyde, Phys. Rev. 1960, 119, 1492-1495. M. Weger, Bell Syst. Tech. J. 1960, 39, 1013-1112. M. J. Frisch, Gaussian09, Revis. B0.01 2010.

A. D. Becke, Phys. Rev. A 1988, 38, 3098-3100.

C. Lee, W. Yang, R. G. Parr, Phys. Rev. B 1988, 37, 785-789.

A. D. Becke, J. Chem. Phys. 1993, 98, 5648-5652.

A. D. Becke, J. Chem. Phys. 1993, 98, 1372-1377.

R. Ditchfield, W. J. Hehre, J. A. Pople, J. Chem. Phys. 1971, 54, 724-728.

W. J. Hehre, R. Ditchfield, J. A. Pople, J. Chem. Phys. 1972, 56, 2257-2261.

V. A. Rassolov, J. A. Pople, M. A. Ratner, T. L. Windus, J. Chem. Phys. 1998, 109, 1223-1229.

P. C. Hariharan, J. A. Pople, Theor. Chim. Acta 1973, 28, 213-222. The PyMOL Molecular Graphics System, Version 2.0
M. D. Hanwell, D. E. Curtis, D. C. Lonie, T. Vandermeersch, E. Zurek, G. R. Hutchison, J. Cheminform. 2012, 4, 1-17. Schrödinger, LLC. 